\title{
STEAM Programming as a Pathway to Foster Positive Academic Self-Efficacy and Positive Self-Concept
}

\author{
Merci N. Best ${ }^{\mathrm{a} 1}$, Robin R. Best ${ }^{\mathrm{b}}$, Cheryl L. Dickter ${ }^{\mathrm{c}}$ \\ ${ }^{a}$ University of Virginia, USA; ${ }^{b}$ Grand Canyon University, USA; ${ }^{\circ}$ The College of William \& Mary, USA
}

\begin{abstract}
Multicultural individuals are underrepresented in the fields of science, technology, engineering, and mathematics (STEM). Therefore, the current study is focused on exploring STEAMtrix, a STEM outof-school time (OST) education program that incorporates the arts (STEAM) for kindergarten through $12^{\text {th }}$ grade (K-12) students. The study explores whether STEAMtrix could lead to interest and awareness of careers within the STEM pipeline. Specifically, the study examined whether the pedagogical and curricular features of STEAMtrix could improve underrepresented students' formation of positive STEM-specific self-efficacy and self-concept. Thirty-eight students from African American and biracial, African American and Caucasian, backgrounds at a medium-sized community center participated in STEAMtrix, an eight-session STEAM OST curriculum. Explicit measures of STEM self-efficacy and both explicit and implicit measures of self-concept were collected before and after programming. Results demonstrated that the pedagogical and curricular features of STEAMtrix increased STEM self-efficacy in some domains and improved implicit self-concept. This study offers insight into how community organizations and school systems can promote early access, positive selfefficacy, and positive self-concept in relation to STEM educational experiences during OST.
\end{abstract}

Keywords: Multicultural, science, technology, engineering, and mathematics (STEM), out-of-school time $(O S T)$, science, technology, engineering, arts, and mathematics (STEAM), kindergarten through 12th grade $(K-12)$, self-efficacy, self-concept

\section{Introduction}

The professional opportunities in science, technology, engineering, and mathematics (STEM) fields are projected to increase at higher rates than those of non-STEM fields (Best, 2016; Fayer, Lacey, \& Watson, 2017; Langdon, Mckittrick, Beede, Khan, \& Doms, 2011). However, multicultural individuals are less likely to continue in pursuit of a STEM degree than their counterparts (Bianchini, 2013; Maton, Sto Domingo, Stolle-Mcallister, Zimmerman, \& Iii, n.d.; Zatz, Gates, Santiago, \& Johnson, 2017). Multicultural individuals are those from racial and ethnic groups that have been shown by the National Science Foundation (NSF) to be underrepresented in health-related sciences on a national basis (Lehming, Gawalt, Cohen, \& Bell, 2013; National Science Foundation \& National Center for Science and Engineering Statistics, 2019). The racial and ethnic groups included within the NSF definition are Blacks or African Americans, Hispanics or Latinos, American Indians or

${ }^{1}$ Corresponding Author: Merci N. Best, University of Virginia, Pharmacology Degree Trainee, University of Virginia, VA 22904, USA. Email: mnb4xd@ virginia.edu

Best, N. M., Best, R. R., \& Dickter, L. C. (2019). STEAM Programming as a Pathway to Foster Positive Academic Self-Efficacy and Positive Self-Concept. Journal of Research in STEM Education, 5(2), 100-118. 
Alaska Natives, and Native Hawaiians and other Pacific Islanders. The term multicultural is rooted in the belief that different cultural or racial groups have equal rights and opportunities in a society, including that to education (Byars-Winston, 2014; Nieto \& Bode, 2012). Multicultural individuals enter the STEM pipeline, but some do not ultimately remain in STEM, which creates gaps that result in the disproportionate number who obtain STEM careers (Griffith, 2010; Huang, Taddese, \& Walter, 2000; Malcom \& Feder, 2016; Maton et al., n.d.; Riegle-Crumb, King, \& Irizarry, 2019).

Eighty-four percent of working professionals in STEM fields are Caucasian or Asian males (Jackson, Charleston, Lewis, Gilbert, \& Parrish, 2017; Lehming et al., 2013), and almost 70\% of full time scientist and engineers are Caucasian (National Science Foundation \& National Center for Science and Engineering Statistics, 2019). The aforementioned statics are a result of numerous factors including lack of early access, poorer educational systems, lack of social capital and status, and lower self-esteem (Ashby, 2006; Funk \& Parker, 2018). Collective findings suggest that there is a pipeline issue with retaining racially diverse STEM talent, as non-cognitive, social-psychological, and demographic factors affect these students' selection and persistence in STEM majors (Berube, Eubanks-Turner, Mosteig \& Zachariah, 2017). In order to address the shortage of U.S. STEM workers, racially diverse talent must be recruited from the American school system and retained in the STEM pipeline (Best, 2016; Fayer et al., 2017; Langdon et al., 2011). There are multiple barriers that lead to this shortage, especially in under-served communities such as resource availability, hiring and retention of quality teachers, and educational enrichment accessibility (Adetunji \& Levine, 2015; Bargagliotti, Herreiner, \& Phillips, 2018). However, it is important to also reimagine kindergarten through 12th grade (K-12) STEM education in ways that are relevant to underrepresented students.

\section{The STEAM Movement}

Dr. Judith A. Ramaley, the former director of the NSF Education and Human Resources Division, is credited with defining the science, technology, engineering, and mathematics curriculum as the acronym STEM (Carmichael, 2017). The STEM curriculum has garnered support from various professional and educational institutes, but there still remains little consensus on how the curriculum should be effectively taught in schools (Eleftheria, Sotiriou, \& Doran Ellinogermaniki Agogi, 2016; Reinholz, 2018; Ting, 2016). The lack of consensus in part, has paved the way for the development of out-of-school time (OST) programs as avenues to supplement what is taught in the traditional academic setting. Since the cultivation of the STEM movement, a number of STEM-based extensions have galvanized. One such extension is STEAM, which advocates for the necessity of the arts within the STEM curriculum (Bequette \& Bequette, 2012; Daugherty, 2013; Madden et al., 2013). Georgette Yakman is the founding researcher and creator of STEAM education (Yakman, 2015). In 2006, she developed the framework and began its implementation in 2007 as a middle and high school engineering and technology teacher (Yakman, 2015).

The integration of art and design in the STEM education conversation has the potential to make STEM more appealing to a wider demographic, including multicultural students, and thus increase overall engagement with STEM fields (Bequette \& Bequette, 2012; Daugherty, 2013; Jolly, 2014; Land, 2013). Many support STEAM, but concerns remain on whether the arts belong and if arts are included, then why not the other humanities (Jolly, 2014; Land, 2013). The STEM to STEAM movement is in part a reflection of collaborations and jointly funded projects through the NSF and National Endowment for the Arts, two predominant federal agencies responsible for the promotion of STEM and the arts respectively (Barrett, Anttila, Ruthmann, Haseman, \& Ghanbari, 2015; Berube et al., 2017; Carroll, 2015; Kuenzi, 2008).

\section{STEAM as a Pathway to Foster Innovation}

The increase of available funding has resulted in development of STEAM programs at the national, state, and local levels (Bush et al., 2016; Daugherty, 2013; Dekhtyar \& Schaffner, 2018; Miel, Portsmore, Maltese \& Paul, 2018). Through a lens of innovation, STEAM-based curricula integrate scientific training with creative development (Madden et al., 2013). The novelty behind the STEAM movement is the shift in perceptions of STEM topics from unapproachable to include creative and real opportunities for expression (Guyotte, Sochacka, Costantino, Walther, \& Kellam, 2014; Miller 
\& Knezek, 2013). Additionally, the arts are a creative learning tool that can serve as a gateway to STEM for multicultural students (Jolly, 2014). Art activities increase motivation, offer more diverse learning opportunities, and provide greater access, all of which increase the probability of STEM success (Jolly, 2014). However, more research needs to examine the effect that STEAM programming has on increasing academic, and even more specifically STEM, success. Self-efficacy and self-concept are two of the most significant predictors of educational success such as performance and effort (Marsh \& Martin, 2011; Pajares, 1996; Valentine, DuBois \& Cooper, 2004). Therefore, it is important to examine these two constructs when evaluating the effectiveness of a STEAM program.

\section{Self-Efficacy}

To ensure that multicultural individuals are adequately represented in STEM careers, their academic self-efficacy must be encouraged and supported as early as the K-12 level (Marra, Rodgers, Shen, \& Bogue, 2009; McClary, Zeiber, Sullivan, \& Stochaj, 2018; Rinn, Miner, \& Taylor, 2013). Selfefficacy refers to situation-specific self-confidence before STEM subject with such as in this context (Bandura, Barbaranelli, Caprara, \& Pastorelli, 1996). Self-belief influences task choice, level of effort, persistence, and subsequent performance (Bandura, 1997; Hajloo, 2014). Self-efficacy is one of the strongest performance domain factors especially in academic settings (Hajloo, 2014; Pajares, 1996). Underdeveloped academic and STEM-specific self-efficacy may be at least partially the result of racial stereotypes targeted towards multicultural students (Reinholz, 2018; Soe \& Yakura, 2008). In order to foster positive academic and STEM-specific self-efficacy, targeted opportunities for early STEM education should ensure that all students are granted opportunities to take courses in school and participate in quality STEM OST programs.

\section{Self-Concept}

In addition, the development of positive self-concept can foster recruitment and retention of multicultural individuals in the choice of pursuing STEM careers (Betz \& Hackett, 1986; Carpi, Ronan, Falconer, \& Lents, 2017; Dabney et al., 2012). Self-concept is represented as judgements of global self-constructed beliefs that reflects one's view of accomplishments, capabilities, values, body, others' responses, events, occasions, and possessions (Bandura, 1997; Hajloo, 2014; Tesser, 2000). In educational systems across the world, improving general feelings of self-concept has been identified as an important goal (Dévai, Katona-Sallay, Pekrun, \& Kalliopuska, 1990; Gwirayi \& Shumba, 2007; Klapp, 2018; Sui-Chu Ho, 2003; Yeung, Craven, \& Ali, 2013). More specifically, individuals and organizations have acknowledged that positive self-concept is associated with desirable educational outcomes, including academic performance (Marsh \& Martin, 2011) and motivation and effort (Thomas \& Gadbois, 2007). Although assessing self-concept using self-report methods is important, previous work examining participation and interest in STEM fields has demonstrated that situational cues affect self-concept. For example, exposing women to ingroup role models in STEM settings increases their implicit but not explicit self-concept (Stout, Dasgupta, Hunsinger, \& McManus, 2011), suggesting that self-concept is more reliably assessed with implicit rather than explicit measures (Markus \& Kunda, 1986). Since there are established measures for explicit and implicit self-concept that can predict different behaviors and intentions (Greenwald et al., 2002), it is important to use both to holistically assess self-concept.

\section{The Development of STEAMtrix}

To address the underrepresentation of multicultural individuals in the STEM pipeline, we developed a novel program that uses the STEAM movement to encourage the development of positive self-efficacy and self-concept in STEM fields. STEAMtrix is a STEM OST education program that incorporates the arts within a science-based curriculum. The STEAM-based programming seeks to encourage student proficiency in both convergent thinking, typically acquired in STEM lessons and divergent thinking, typically acquired in the arts (Guilford, 1956; Land, 2013). These contrasting approaches are cultivated during project-based learning, which is designed to develop students' interest and awareness of careers within the STEM pipeline. The mission of STEAMtrix is to provide $\mathrm{K}-12$ students with innovative opportunities to participate in STEAM activities outside of the traditional academic setting. Although STEAMtrix serves all students, students from 
underrepresented populations in STEM fields, including multicultural individuals and females, are the targeted populations. The pedagogical and curricular features of STEAMtrix provide targeted opportunities that promote early access, positive STEM self-efficacy, and positive self-concept. In doing so, the STEAMtrix pedagogical and curricular features respond to the unique needs of all students, specifically multicultural individuals.

The Pedagogical Features of STEAMtrix

The overarching pedagogical features of STEAMtrix are the cultural relevancy of STEAMtrix and the curriculum, the integrative approach by which instructors teach the curriculum, and the inclusive environment that promotes a sense of belonging. A national culturally relevant need is for a more racial and gender diverse STEM pipeline. As a culturally relevant response, STEAMtrix seeks to expose underrepresented students to hands-on STEM activities and engagement with STEM fields. Further, the STEAMtrix curriculum is centered around a topic that many students have familiarity. Throughout the lessons, students are provided with the resources to build upon STEAM concepts. This promotes the development of more positive self-efficacy and self-concept as students are made aware of STEM career possibilities. Therefore, exposure, experience and engagement, some of the unique needs of multicultural students (Byars-Winston, 2014; Nieto \& Bode, 2012), are met as a conduit toward the selection of future STEM careers.

Currently, school-based curricula introduces STEM in a siloed approach, wherein each content area is taught mutually exclusive from the next (Eleftheria et al., 2016). In contrast, STEAMtrix integrates STEAM through language, hands-on activities, and presentation opportunities. Therefore, within the STEAMtrix framework, learning is incubated and explored at each student's level, allowing multiple age groups to engage with integrated STEAM fields. In doing so, concepts particular to each content area-based session are reinforced throughout the duration of the curriculum. For example, the presentation session built into the curriculum integrates and highlights the cumulative work that was done throughout the program. Each content areas session, leading to the final presentations, highlights a multicultural individual from popular culture who has received a higher learning degree in the content field related to the session. The virtual exposure to multicultural individuals from STEM career backgrounds paired with those who instruct in person as guest speakers, presenters, and/or volunteers further enhances the student's self-efficacy and self-concept, as they see someone who resembles them as a STEM professional. The connections students make with these individuals contributes to their empowerment and development of more positive feelings towards STEM fields as they now have models of success in STEM. Most academic settings seek to employ a pedagogy of belonging to meet the student's psychological need to feel as if they are accepted and belong (Beck \& Malley, 1998). However, STEAMtrix has taken the sense of belonging one step further as students are made aware that they belonged in STEAMtrix, and in STEM careers. For some students, their STEAMtrix experience was the first time they had been exposed to a person in the STEM field that resembled them.

\section{The Curricular Features of STEAMtrix}

The STEAMtrix curriculum can be adapted for multiple age groups. The STEAM units are taught in the same order with the same expectation for the students to achieve benchmarks of skill (behavior, analytical, communication, and teamwork skills), knowledge, and dispositional goals. The STEAMtrix goals are based in the performance indicators (quantitative and qualitative) and objectives (program, cognitive, affective, behavioral, developmental, instructional objectives). The differences of the curricular features are based in the expectation of how the students present their outcomes. For example, more junior students can draw as an alternative to writing in their notebooks throughout the curriculum. The first session, of STEAMtrix the students were introduced to the program, team building, and how to operate the program measures. Concurrent sessions two through six are content based where STEAM is integrated. In these sessions, students are presented with project-based activities that provide spaces for their empowerment of themselves and the communities they represent. Session seven involves the preparation and presentation as students demonstrate knowledge of various completed projects to peers, family, and community partners. 
During the final session, the students complete the post programming measures and receive a certificate of completion.

This paper will describe how STEAMtrix's pedagogical and curricular features aim to foster the formation of positive STEM self-efficacy and self-concept that sustains multicultural students' interest and awareness of careers within the STEM pipeline. In addition, this paper also assesses the effectiveness of the program in achieving these goals. Previous research suggests that effective STEM programs should use a project-based, culturally responsive, pedagogy-centered STEM curriculum to help students develop strong STEM self-efficacy (Davis \& Hardin, 2013). According to the National Research Council, the following goals must be met in an effective STEM OST program:

1. engage young people intellectually, academically, socially and emotionally

2. respond to young people's interest, experiences and cultural practices

3. connect STEM learning in out-of-school, home, and other settings (Caplan, 2018, p.2).

STEAMtrix was designed to accomplish these goals by incorporating the visual and performing arts within the STEM paradigm to encourage student interest and awareness of careers within the STEM pipeline (Segarra, Natalizio, Falkenberg, Pulford, \& Holmes, 2018). Across the country some schools at the K-12 grade level have integrated art into STEM curricula with increased reported student success (Krigman, 2014; Williams, 2014). STEM and arts integration ideas have been supported by lawmakers, who launched a STEAM Caucus in the U.S. House of Representatives that advocates for arts education and integration being essential in producing the future workforce (Krigman, 2014). The integration of arts into the STEM curriculum is particularly impactful for multicultural students, who are often labeled as "at risk" (Barone, Bresler, \& Betts, 2006; Catterall, Dumais, \& Hampden-Thompson, 2012). Arts involvement reinforces multicultural students' achievement in STEM, which could eventually narrow the gap in the STEM workforce (Catterall et al., 2012; Rabalais, 2014; Sousa \& Pilecki, 2013; Van Der Veen, 2012). In addition, increased self-efficacy and positive attitudes, particularly among low income students, has also been linked to increases in arts instruction, which further supports arts' potential role in encouraging STEM interest (Barone et al., 2006). Furthermore, empirical data and theoretic foundations have connected arts to cognition, student performance, enhanced creativity, deeper learning, and cultural empathy (Rabalais, 2014). A study using the National Assessment of Educational Progress, similar to prior research studies, identified a relationship between increased exposure to the arts and performance in STEM subjects, especially for multicultural students (Rabalais, 2014). In order for traditional STEM programs to be effective it is argued that positive, engaging or interactive environmental factors are needed, among additional factors, to influence student interest (Byars-Winston, 2014). Therefore, arts may be the missing component in the charge of increasing the number of multicultural individuals recruited and retained in the STEM workforce (Rabalais, 2014).

The overall goal of STEAMtrix is for underrepresented students to envision themselves as successful in a variety of STEM careers. The pedagogical and curricular features of STEAMtrix that feature the culturally relevant curriculum used in this case study provide individuals with the opportunity to explore STEAM fields over the course of an eight-session program. The goal of the current study was to assess the effectiveness of the pedagogical and curricular features of STEAMtrix in enhancing self-efficacy and self-concept. It was hypothesized that the program would lead to increased positive STEM self-efficacy as measured by an individual's interest and awareness of careers in the STEM pipeline. Both explicit and implicit self-concept were measured. Importantly, research has demonstrated interventions targeted at individuals from social groups underrepresented in STEM fields improve implicit but not explicit self-concept (Stout et al., 2011). Thus, it was expected that the current program would only improve implicit self-concept. 


\section{Method}

\section{Participants}

Thirty-eight African-American and two biracial, African-American and Caucasian, K-12 students participated in eight sessions of STEAMtrix at the Salvation Army Boys \& Girls Club in Richmond, Virginia's East End. These multicultural students ranged in age six to 13. There was a gender imbalance with 27 girls and 11 boys. The sessions were held one day a week, over the course of eight weeks during the Boys \& Girls Club Summer Program, which is subdivided into four, twoweek sessions (June 17th - August 16th). The then Program Director from STEAMtrix collaborated with an Associate Professor in the Department of Psychology at William \& Mary, a mid-sized public university near the area to create materials to assess the efficacy of the program. All procedures were approved by the university's Protection of Human Subjects Committee and the Program Director of the Boys \& Girls Club. Students were given the opportunity to self-selectively take part in the study. Consent forms were completed by their guardians. Before pre-program measures were collected at the Boy \& Girls Club, students completed informed assent forms that were read aloud by the researcher prior to the study. Students were eligible for the study if they turned in a completed (1) STEAMtrix application, (2) informed consent form, and (3) informed assent form. Following the reading of the assent form, students were invited to ask questions about the procedure. Students were told that they had the right to not participate in the study, at their choosing. Further, they would not be penalized for refusal to answer any of the questions they did not wish. The privacy and confidentiality of all students will always be maintained, through the use of encrypting the data with codes that protect the identity of each participant. The researchers decided to make student comfort a priority while providing information through use of a computerized survey system. The risk in this study was considered to be minimal, since the probability and magnitude of harm or discomfort anticipated in the research was not greater than that experienced ordinarily in daily life (Binik \& Weijer, 2014).

\section{Materials}

Self-Efficacy

To assess explicit STEM self-efficacy, the students were asked to complete a self-report measure run through Survey Monkey, an online survey software that provides customizable surveys. The questions from the survey were extrapolated from previously validated surveys (Erkut \& Marx, 2005; Faber, Walton, Booth, Parker, \& Corn, 2013; U.S. Bureau of Labor Statistics, 2009; Unfried, Faber, Stanhope, \& Wiebe, 2015). As a measure of STEM-specific self-efficacy the students indicated all related subjects they liked and could obtain as a job.

Self-Concept

Explicit. To assess explicit self-concept, the students were asked how much they thought the following sentences described them on a five-point Likert scale, (1) very probably not to (5) definitely (Mcleod, 2008). The sentences were: "If I work hard I can accomplish my goals...", "I am just as smart as other kids my age...", and "I can go to college...".

Implicit. The Implicit Association Test (IAT; Greenwald, Mcghee, \& Schwartz, 1998) assesses the basic evaluative associations people hold toward attitude objects without relying on self-report. The IAT in the current study is used as an implicit measure of a students' implicit self-concept (Greenwald et al., 1998; Nosek, Banaji, \& Greenwald, 2002). The Self-Concept IAT (Custom Items) assesses the degree to which respondents implicitly associate attributes (e.g., pleasant, unpleasant) with personal terms (e.g., self, others) gathered from students (e.g., name, hometown, etc.) to use as stimuli representing the "me" and "other" target categories (Greenwald et al., 2002; Greenwald, Nosek, \& Banaji, 2000). This paradigm presents students with the opportunity to add in personal information to be used within the paradigm. Students are asked to categorize attributes belonging to Pleasant vs. Unpleasant and items belonging to categories Self vs. Others into predetermined categories via keystroke presses. The basic task is to press a left key (E) if an item (e.g. "pleasure") belongs to the category presented on the left (e.g. "Pleasant") and to press the right key (I) if the word 
(e.g. "gloom") belongs to the category ("Unpleasant") presented on the right. For practice, students sort items into the categories "Pleasant vs. Unpleasant" and the categories "Self vs. Other". For the test, students are asked to sort items into the paired/combined categories (e.g. "Self OR Pleasant" on the left vs. "Other OR Unpleasant" on the right). Pairings are reversed for a second test (e.g. "Other OR Pleasant" on the left vs. "Self OR Unpleasant" on the right). Order is counterbalanced by group number. After the students completed the Self-Concept IAT (Custom Items), they were automatically taken to the previously described self-report survey

\section{Procedure}

All parts of the study were run through Inquisit by Millisecond Software (Greenwald, Nosek, \& Banaji, 2003), which is used by behavioral scientists to create and administer numerous cognitive and social reaction-time based measures. In order to obtain data on the effectiveness of STEAMtrix, measures were assessed at two time points: Time 1, before programming sessions and Time 2, after programming sessions. At each time point, students completed the measures seated at a private computer station in small groups of two to four. Students were told that they would be playing a game, of which the purpose was to examine their responses to words. First, students completed the Self-Concept IAT (Custom Items) behavioral task that took approximately 5-10 minutes (Nosek et al., 2002). Second, students completed an additional behavioral task that took approximately 5-10 minutes; data from this task are not included in the current paper. Third, students completed the STEM Computer Task self-report survey that took approximately 15 minutes. During the STEM Computer Task students also provided information about their race, age, and gender. When complete, students were thanked, given a snack, and dismissed.

\section{Results}

The Time 1 measure included 32 responses. The Time 2 measure included 35 responses. Only students who completed both measures were included in the analysis below $(n=29)$. The results were analyzed using Statistical Package for the Social Sciences (SPSS) software. Figures one through four were made using GraphPad Prism 8. Figure five was created with BioRender.com.

STEM Self-Efficacy

In order to examine changes in explicit measures from Time 1 to Time 2, a series of 2-tailed paired Student's t-tests were conducted. As demonstrated in Figure 1, results with statistical significance revealed that the ability to like Technology (Pair 2) was greater at Time $2(\mathrm{M}=0.52, \mathrm{SD}=$ $0.51)$ than at Time $1(\mathrm{M}=0.31, \mathrm{SD}=0.47), \mathrm{t}(28)=-2.27, \mathrm{p}=.031$. The results with statistical significance revealed that the ability to obtain a job in Science (Pair 6) was greater at Time $2(\mathrm{M}=0.48, \mathrm{SD}=0.51)$ than at Time $1(\mathrm{M}=0.22, \mathrm{SD}=0.42), \mathrm{t}(28)=-2.56, \mathrm{p}=.017$. The results with marginal significance revealed that the ability to obtain a job in Technology (Pair 7) was greater at Time $2(\mathrm{M}=0.48, \mathrm{SD}=$ $0.51)$ than at Time $1(\mathrm{M}=0.30, \mathrm{SD}=0.47), \mathrm{t}(28)=-1.73, \mathrm{p}=.096$. The results with marginal significance revealed that the ability to obtain a job in Engineering (Pair 8) was greater at Time $2(\mathrm{M}=0.41$, SD $=0.50)$ than at Time $1(\mathrm{M}=0.22, \mathrm{SD}=0.42), \mathrm{t}(28)=-1.72, \mathrm{p}=.096$. No other tests were statically or marginally significant. 


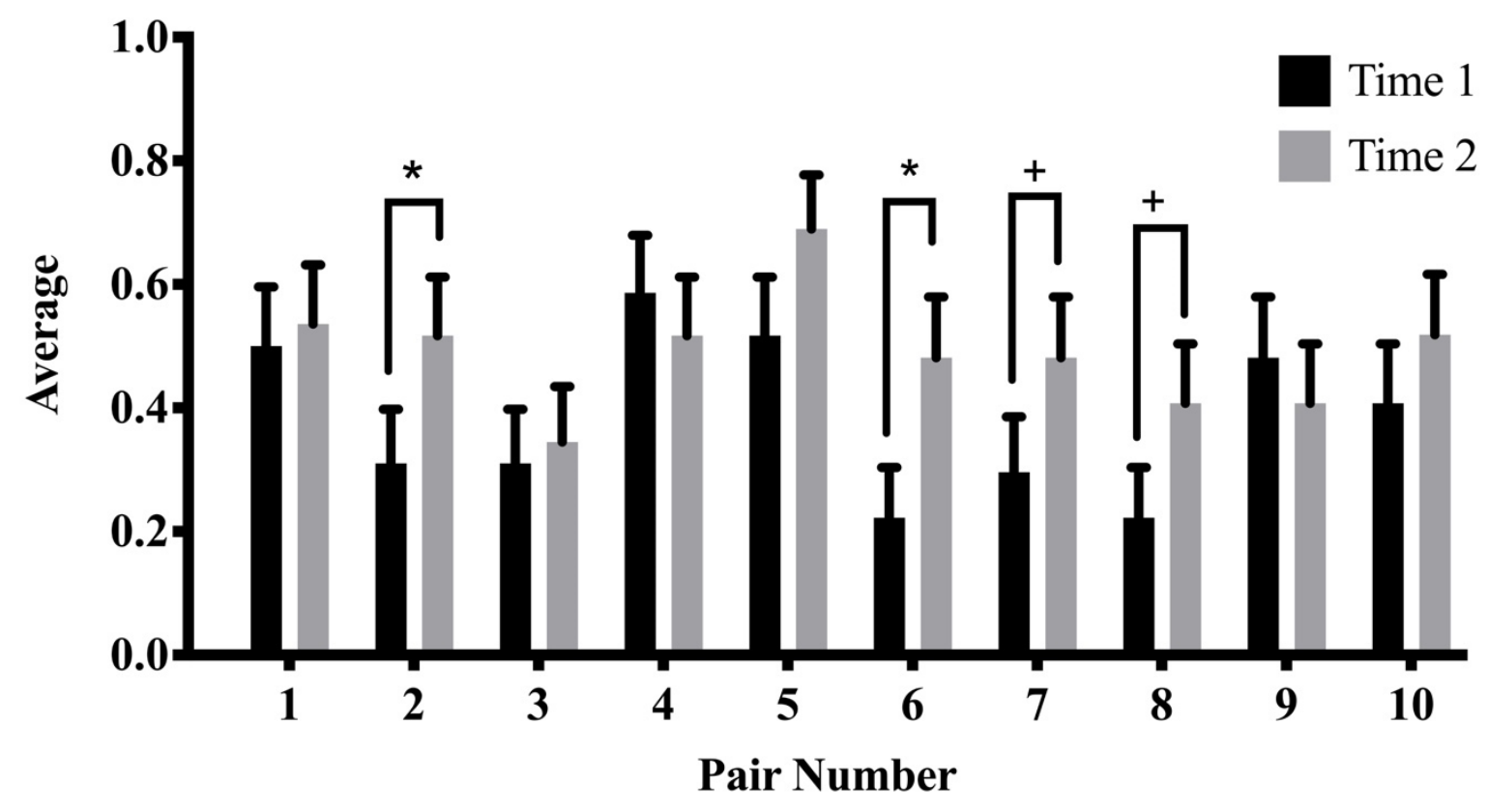

Pair 1 = I can like science.

Pair 2 = I can like technology.

Pair 3 = I can like engineering.

Pair 4 = I can like art.

Pair $5=$ I can like mathematics.

Pair $6=$ I can obtain a job in science.

Pair 7 = I can obtain a job in technology.

Pair $8=\mathrm{I}$ can obtain a job in engineering.

Pair 9 = I can obtain a job in art.

Pair $10=$ I can obtain a job in mathematics.

Figure 1. Explicit Measures Demonstrate Improved STEM-Specific Self-Efficacy. Interleaved bar graphs show mean value with standard error mean for the cohort of STEAMtrix students $(n=27-29)$ determined using 2-tailed paired Student's t-test, which found significant $\left({ }^{*}\right)$, marginal $(+)$, or no effects. Pair numbers correspond to questions on the self-report explicit measure of STEM self-efficacy.

\section{Self-Concept}

Explicit. As demonstrated in Figure 2, when asked if students felt they could accomplish their goals if they worked hard (Pair 1), there were no differences between scores at Time $1(\mathrm{M}=1.63$, SD $=1.01)$ and Time $2(\mathrm{M}=1.56, \mathrm{SD}=0.85)$. There was no difference between Time $1(\mathrm{M}=2.07, \mathrm{SD}=$ 1.01) and Time $2(\mathrm{M}=1.81, \mathrm{SD}=0.79)$ on students' feelings of being just as smart as other kids their age (Pair 2). There was no difference between Time $1(\mathrm{M}=1.44, \mathrm{SD}=0.92)$ and Time $2(\mathrm{M}=1.24$, SD $=0.52$ ) on students' feelings that they can go to college (Pair 3). 


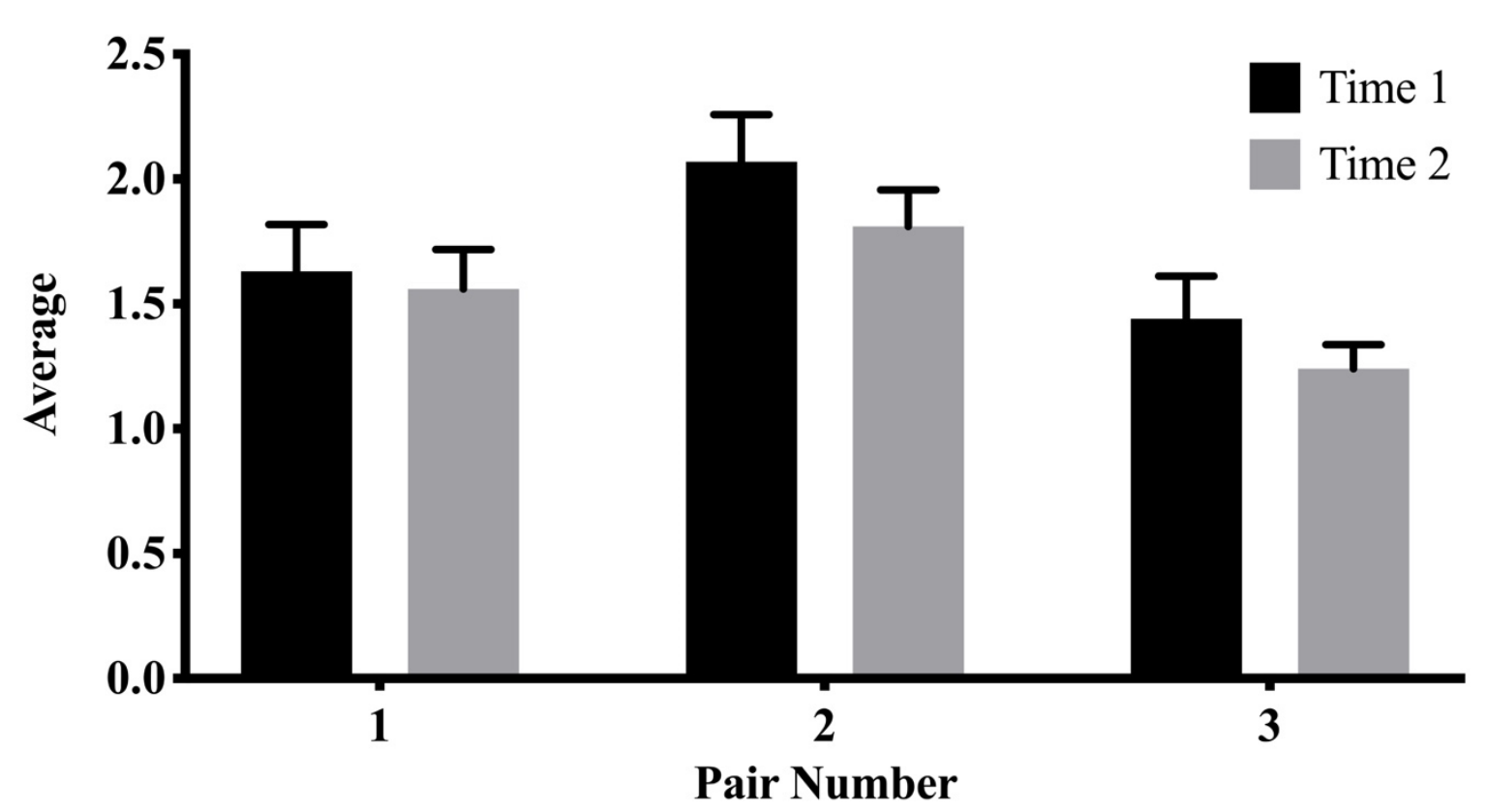

Pair 1 = If I work hard I can accomplish my goals.
Pair 2 = I am just as smart as other kids my age.
Pair 3 = I can go to college.

Figure 2. Explicit Measures Demonstrate No Change in Self-Concept. Interleaved bar graphs show mean value with standard error mean for the cohort of STEAMtrix students $(\mathrm{n}=29)$ determined using 2-tailed paired Student's t-test, which found no effects. Pair numbers correspond to questions on the self-report explicit measure of STEM self-concept.

Implicit. The strength of an association between concepts was measured by the standardized mean difference score of the 'hypothesis-inconsistent' pairings and 'hypothesis-consistent' pairings, referred to as a difference or d-score (Greenwald et al., 2003). In general, the more positive the d-score the stronger the association between the 'hypothesis-consistent' pairings, like 'Self-Pleasant' and 'Other-Unpleasant' than for the opposite pairings. Negative d-scores suggest a stronger association between the 'hypothesis-inconsistent' pairings like 'Other-Pleasant' and 'Self-Unpleasant'. The IAT was scored using Greenwald et al.'s (2003) revised method. Accordingly, two students with greater than $10 \%$ of latencies less than 300 milliseconds, on the IAT were eliminated from analysis, because their short reaction times indicated that they were likely not paying attention to the instructions and were just hitting the keys as fast as possible without trying to be accurate. The difference scores were calculated as the difference between Time 2 and Time 1. As demonstrated in Figure 3, for the SelfConcept IAT (Custom Items), the mean calculated d score was $0.24(S D=0.30)$ at Time 1 and 0.02 (SD $=0.47$ ) at Time 2 . These means were different from zero at Time $1, \mathrm{t}(24)=2.63, \mathrm{p}=.041$, and marginally different from zero at Time $2, \mathrm{t}(22)=2.03, \mathrm{p}=.056$, indicating a negative implicit association with self-concept. These scores improved, however from Time 1 to Time 2, with the means showing a marginally significant difference, $\mathrm{t}(24)=1.96, \mathrm{p}=0.061$, indicating improved implicit association with self-concept. 


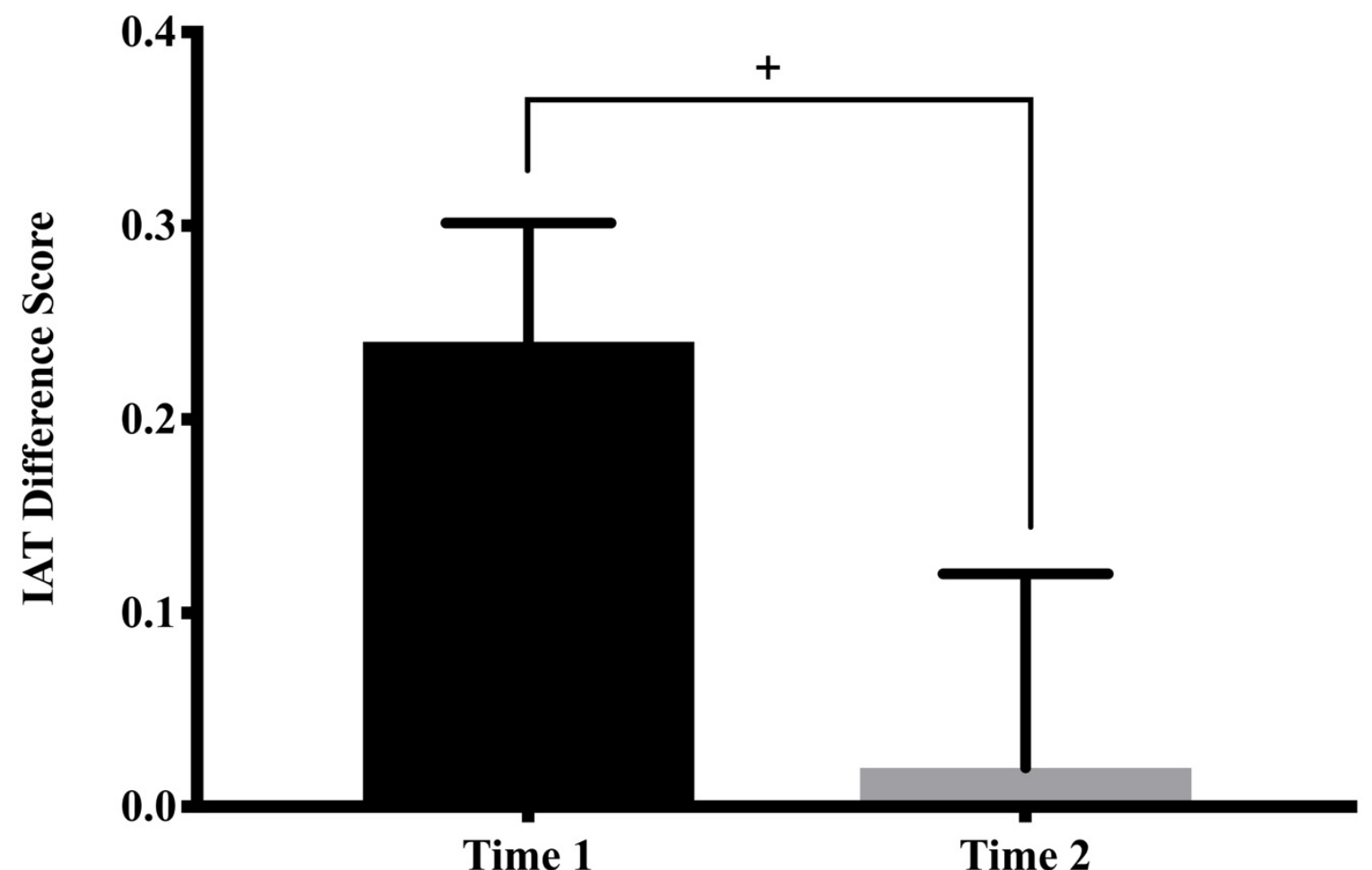

Figure 3. Implicit Measures Demonstrate Improved Self-Esteem. Interleaved bar graphs show calculated mean IAT difference score values with standard error mean for the cohort of STEAMtrix students $(n=22-24)$ determined using 2-tailed paired Student's t-test, which found marginal (+) effects. 


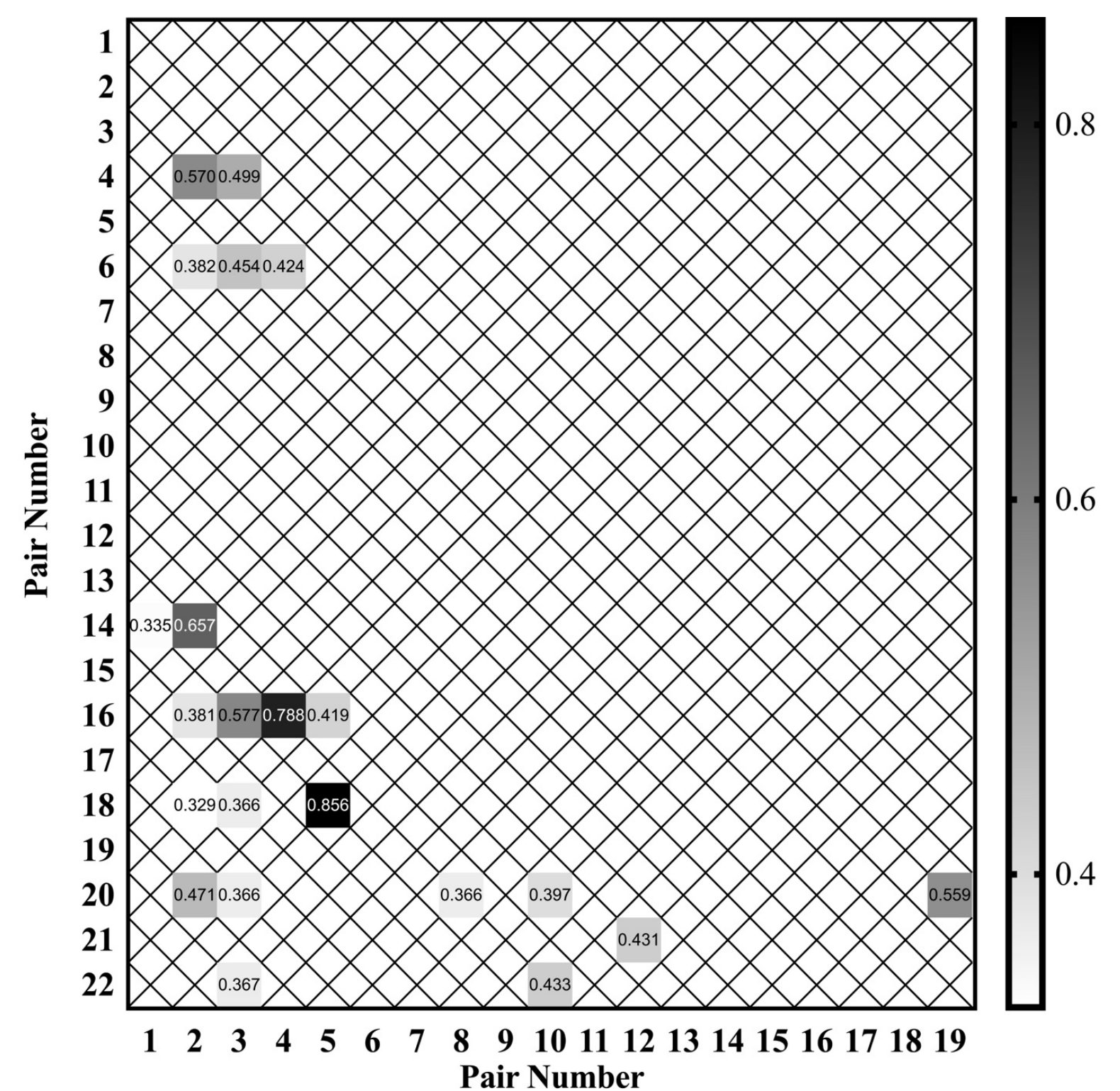

\begin{tabular}{|l|}
\hline Pair 1 = I can like science (Time 1). \\
Pair 2 = I can like science (Time 2). \\
Pair 3 = I can like technology (Time 1). \\
Pair 4 = I can like technology (Time 2). \\
Pair 5 = I can like engineering (Time 1). \\
Pair 6 = I can like engineering (Time 2). \\
Pair 7 = I can like art (Time 1). \\
Pair 8 = I can like art (Time 2). \\
Pair 9 = I can like mathematics (Time 1). \\
Pair 10 = I can like mathematics (Time 2). \\
Pair 11 = IAT (Time 1). \\
Pair 12 = IAT (Time 2).
\end{tabular}

Pair 13 = I can obtain a job in science (Time 1). Pair 14 = I can obtain a job in science (Time 2). Pair 15 = I can obtain a job in technology (Time 1). Pair 16 = I can obtain a job in technology (Time 2). Pair $17=\mathrm{I}$ can obtain a job in engineering (Time 1). Pair 18 = I can obtain a job in engineering (Time 2). Pair $19=$ I can obtain a job in art (Time 1). Pair $20=\mathrm{I}$ can obtain a job in art (Time 2). Pair 21 = I can obtain a job in mathematics (Time 1). Pair 22 = I can obtain a job in mathematics (Time 2).

Figure 4. Correlation Matrix. Gray scale heat map shows the relative intensity of values as the correlation between the two pairs for the cohort of STEAMtrix students. In this heatmap the highest values relative to the other present numbers are black and the lowest are white. Therefore, black squares indicate a strong correlation between the two pairs, whereas white indicates a weaker correlation. Values that did not have a statistically meaningful correlation are blank with an X. 


\section{Discussion}

This study was the first to assess the effectiveness of STEAMtrix, a STEM OST education program that incorporates the arts. STEAMtrix was offered as an eight-session summer curriculum at the Salvation Army Boys \& Girls Club in Richmond, Virginia's East End to determine if consistent participation could result in the formation of positive STEM-self-efficacy and self-concept in African American students. Our results demonstrate that the pedagogical and curricular features of STEAMtrix increased STEM self-efficacy in some domains such as the self-reported interest in technology as a field and awareness of opportunities to pursue a career in science. In addition, although there were no changes in explicit self-concept as a result of the program, implicit selfconcept improved. These preliminary findings, as collectively demonstrated in Figure 4, suggest that pedagogical and curricular features of STEAMtrix, as an example of STEM OST programs that incorporate the arts may have the potential to shift self-efficacy and implicit self-concept, which are some of the most important predictors of educational success (Marsh \& Martin, 2011; Pajares, 1996; Valentine et al., 2004).

The current study partially supports previous work demonstrating that when individuals participate in STEM OST programs, their overall interest, capacity, and engagement in STEM rises by an equivalent amount to their participation (Bevan \& Michalchik, 2013; Dabney et al., 2012). For example, we found rises in self-efficacy and self-concept from students who regularly participated, and were present for both measures. In the current study, students indicated, compared to Time 1 , they were more interested in technology and were more aware of the opportunities to pursue a science, technology or engineering career. These changes in STEM self-efficacy are important as self-efficacy is one of the strongest performance domain factors in academic settings (Hajloo, 2014; Pajares, 1996). Although we cannot over-interpret these findings to suggest they will translate across all STEM programs, providing underrepresented populations in STEM with OST programs such as STEAMtrix may help foster positive STEM-self-efficacy and self-concept.

The finding in our study that implicit self-concept was improved as a function of the program is encouraging, as a positive self-concept is associated with stronger academic performance as well as greater motivation and effort in school settings (Marsh \& Martin, 2011; Thomas \& Gadbois, 2007). However, as hypothesized, the current study did not find a difference between Time 1 and Time 2 in terms of explicit self-concept. These findings are consistent with previous research demonstrating that interventions targeting groups that are underrepresented in STEM fields improve implicit self-concept but do not affect explicit self-concept perhaps due to ingroup role models as course instructors, guest speakers, presenters and volunteers (Stout et al., 2011). There are also other factors that may have led to these null results including the season, the ages of the population, and the duration of programming. During summer months, most students in traditional academic settings are no longer receiving regular curricular enrichment. During summer months, most students in traditional academic settings are no longer receiving regular curricular enrichment, which may result in lowering of their explicit self-concept baseline and decrease the likelihood of detecting a shift between Time 1 and Time 2 .

Therefore, future studies should continue to investigate the effects of interventions that are concurrent with the academic school year. Another explanation for the null results could be the ages of the students in the study. The STEAMtrix curriculum is flexible and can be taught to all within the K-12 stages of the pipeline. Since no students over the age of 13 were included in the study, the data were limited to what could be delineated from younger students. Future studies could address this explanation by including representative populations across the K-12 spectrum. Finally, the acute nature of this study, one day a week across eight sessions may have contributed to the difficulty in identifying a shift within the relatively short time frame of the program. In fact, each age group only had one hour per content area, which is a very short period for instruction and completion of an activity. Studies that follow this framework should continue to investigate the effects of interventions on explicit and implicit self-concept concurrent with regular enrichment, different populations, and 
with longer programs.

Our findings underscore the importance of using both explicit and implicit measures to assess self-concept. Together, our findings suggest that programs such as STEAMtrix can potentially shift both explicit STEM self-efficacy and implicit self-concept. Specifically, these results highlight the impact of pedagogical implications, namely culturally responsive pedagogy and culturally relevant curriculum that is foundational to STEAMtrix. In designing the STEAMtrix curriculum to be culturally responsive, it meets the interests and needs of a diverse group of students. The culturally relevant curriculum is tailored to the experiences of communities to ensure a connection and sense of belonging. Students are provided with foundational opportunities to engage with STEM fields. Importantly, STEM professionals from racially diverse populations serve as examples that it is feasible for individuals from their racial background to be sustained in the STEM pipeline on through STEM careers.

\section{Limitations of This Study}

There are several limitations of the current study. First, we were only able to obtain a small sample size.The requirement to turn in paperwork to participate in the STEAMtrix program limited our access to students. Additionally, the small sample size was likely related to some of our marginally significant findings, which may become statistically significant with more statistical power. Second, the nature of the repeated measures design was another limitation in the current study. That is, our results could have been obtained because at Time 2 the students had already completed the measures of interest. Although we think this is unlikely given that STEM-specific self-efficacy and implicit self-concept improved while explicit self-concept did not change, consistent with our hypotheses. However, future research should use a control group with only a post-test to assess causality. Third and finally, the current study only examined able-bodied African American students. There are a number of other underrepresented groups: additional racial minorities as defined by the NSF; women; and those with different abilities (Lehming et al., 2013; National Science Foundation \& National Center for Science and Engineering Statistics, 2019). These populations should be included in future studies, and as the focus in increasing representation in the STEM pipeline. In addressing these limitations, future research should attempt to replicate these findings.

\section{Conclusions and Future Study}

As a result of the current study's limitations, several questions still remain. First, how does culturally competent pedagogy and problem-based learning intersect in both STEM and art education (Bequette \& Bequette, 2012). Second, how can student engagement, learning, and interest be fostered by more integrated art and STEM teaching? Third, what role do STEM OST programs play in student intention to pursue STEM-related careers? In a future study, a STEAM framework can be used to answer lingering questions while analyzing the merit of other OST program models. If used as a model, it is important to note that there will be obstacles in developing programs that meet the needs of all individuals (Grossman \& Porche, 2014). Future research using this framework can examine how changes in implicit self-concept can predict future behaviors and intentions to pursue STEM careers (Greenwald et al., 2002). Additional studies can address how students engage STEAM ideas as they are recruited and retained in the STEM pipeline. Within this framework it is important that key components of design thinking in both art and STEM disciplines are conceptualized to isolate overlapping cognitive and procedural dispositions.

Together the results of the current study provide some preliminary evidence that the culturally responsive pedagogy and culturally relevant curriculum of STEAMtrix, a STEM OST education program that incorporates the arts can increase STEM self-efficacy and implicit self-concept (Figure 5). Although this study has important limitations, it suggests that additional research can be done to replicate the current results and examine generalizability to other STEM OST programs. Programs like STEAMtrix could potentially increase interest and awareness of the opportunities in the STEM pipeline, eventually leading to the recruitment, and retention of underrepresented groups, which will strengthen the STEM workforce in the U.S. 


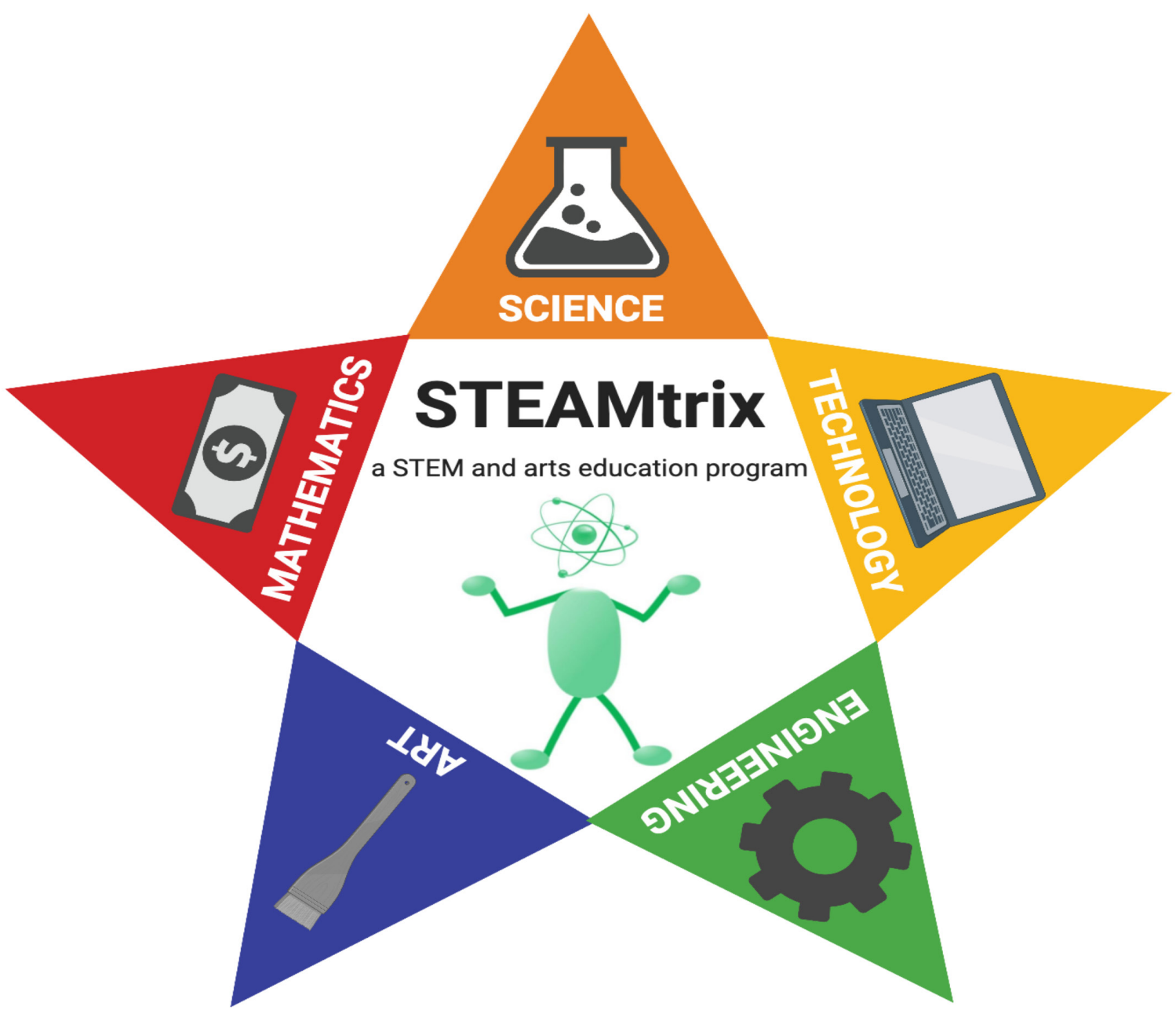

Figure 5. STEAMtrix Summary Figure. STEAMtrix (white), a STEM and arts OST education program is at the intersection of science (orange), technology (yellow), engineering (green), art (blue), and mathematics (red).

Disclosure Statement: Merci N. Best and Robin R. Best declare that they are the co-founders of STEAMtrix. Merci N. Best is also the founder of STEAMKITX. This work was not funded by either organization. Cheryl L. Dickter declares that she has no relevant or material financial interests that relate to the research described in this paper. 


\section{References}

Adetunji, O., \& Levine, R. (2015). Developing Eefective STEM Animations: Application of a multimedia learning theoretical framework. Journal of Research in STEM Education, 1(2), 106-124.

Ashby, C. M. (2006). Science, technology, engineering, and mathematics trends and the role of federal programs. Washington: Committee on Education and the Workforce. House of Representatives. Retrieved from www.gao.gov/cgi-bin/getrpt?GAO-06-702T.

Bandura, A. (1997). Self-efficacy : the exercise of control. New York: W H Freeman/Times Books/ Henry Holt \& Co. Retrieved from http://psycnet.apa.org/record/1997-08589-000

Bandura, A., Barbaranelli, C., Caprara, G. V., \& Pastorelli, C. (1996). Multifaceted impact of self-efficacy beliefs on academic functioning. Child Development, 67(3), 1206-1222. https://doi.org/10.1111/j.1467-8624.1996. tb01791.x

Bargagliotti, A., Herreiner, D., \& Phillips, J. A. (2018). Breaking boundaries: pressing issues in equity, computing, and problem-solving in STEM undergraduate education. Retrieved from https://www.aps.org/about/governance/ letters/scotus.cfm

Barone, T., Bresler, L., \& Betts, J. D. (2006). Multimedia arts learning in an activity system: New literacies for at-risk children. International Journal of Education \& the Arts, 7(7), 1-43.

Barrett, T., Anttila, E., Ruthmann, S. A., Haseman, B., \& Ghanbari, S. (2015). The arts learning across disciplines: A collective case study of two university programs that integrate the arts with STEM. International Journal of Education \& the Arts, 16(7), 1-21.

Beck, M., \& Malley, J. (1998). A pedagogy of belonging. Reclaiming Children and Youth.

Bequette, J. W., \& Bequette, M. B. (2012). A Place for Art and Design Education in the STEM Conversation. Art Education, 65(2), 40-47. https://doi.org/10.1080/00043125.2012.11519167

Berube, D., Eubanks-Turner, C., Mosteig, E., \& Zachariah, T. (2017). A tale of two programs: broadening participation of underrepresented students in STEM at Loyola Marymount university. Journal of Research in STEM Education, 4(1), 13-22.

Best, M. (2016). Over 400,000 potential unfilled stem jobs: houston we have a problem! Retrieved December 28, 2018, from https://pulitzercenter.org/reporting/over-400000-potential-unfilled-stem-jobs

Betz, N. E., \& Hackett, G. (1986). Applications of Self-Efficacy Theory to Understanding Career Choice Behavior. Journal of Social and Clinical Psychology, 4(3), 279-289. https://doi.org/10.1521/jscp.1986.4.3.279

Bevan, B., \& Michalchik, V. (2013). Where It Gets Interesting: Competing Models of STEM Learning after School. Afterschool Matters, 17, 1-8. Retrieved from https://eric.ed.gov/?id=EJ1003837

Bianchini, J. A. (2013). Expanding underrepresented minority participation: America's science and technology talent at the crossroads. Science Education, 97(1), 163-166.

Binik, A., \& Weijer, C. (2014). Why the debate over minimal risk needs to be reconsidered. Journal of Medicine and Philosophy, 39(4), 387-405. https://doi.org/10.1093/jmp/jhu020

Bush, S. B., Cook, K. L., Ronau, R. N., Rakes, C. R., Mohr-Schroeder, M. J., \& Saderholm, J. (2016). A Highly Structured Collaborative STEAM Program: Enacting a Professional Development Framework. Journal of Research in STEM Education, 2(2), 106-125.

Byars-Winston, A. (2014). Toward a Framework for Multicultural STEM-Focused Career Interventions. The Career Development Quarterly, 62(4), 340-357. https://doi.org/10.1002/j.2161-0045.2014.00087.x

Caplan, M. (2018). Assessment of the impact of summer steam programs on high school participants' content knowledge and attitude towards STEAM careers. Retrieved from https://docs.lib.purdue.edu/cgi/viewcontent. cgi?article $=1020 \&$ context $=$ aseeil-insectionconference

Carmichael, C. C. (2017). A state-by-state policy analysis of STEM education for K-12 public schools. Seton Hall University. Retrieved from https://scholarship.shu.edu/dissertations/2297

Carpi, A., Ronan, D. M., Falconer, H. M., \& Lents, N. H. (2017). Cultivating minority scientists: Undergraduate research increases self-efficacy and career ambitions for underrepresented students in STEM. Journal of Research in Science Teaching, 54(2), 169-194. https://doi.org/10.1002/TEA.21341

Carroll, M. (2015). Stretch, dream, and do-a $21^{\text {st }}$ century design hhinking camp; STEM journey. Journal of Research in STEM Education, 1(1), 59-70. 
Catterall, J. S., Dumais, S. A., \& Hampden-Thompson, G. (2012). The Arts and Achievement in At-Risk Youth: Findings from Four Longitudinal Studies. Washington. Retrieved from https://www.arts.gov/sites/default/ files/Arts-At-Risk-Youth.pdf

Dabney, K. P., Tai, R. H., Almarode, J. T., Miller-Friedmann, J. L., Sonnert, G., Sadler, P. M., \& Hazari, Z. (2012). Out-of-School Time Science Activities and Their Association with Career Interest in STEM. International Journal of Science Education, 2(1), 63-79. https://doi.org/10.1080/21548455.2011.629455

Daugherty, M. K. (2013). The Prospect of an A" in STEM education. Journal of STEM Education, 14(2), 10-15.

Davis, K. E., \& Hardin, S. E. (2013). Making STEM fun: How to organize a STEM camp. Teaching Exceptional Children, 45(4), 60-67.

Dekhtyar, A., \& Schaffner, A. (2018). Cross-disciplinary studies minors as a new vehicle to enhance STEAM programs. California Polytechnic State University. Retrieved from http://catalog.calpoly.edu/collegesandprograms/ collegeofsciencemathematics/statistics/

Dévai, M. K., Katona-Sallay, H., Pekrun, R., \& Kalliopuska, M. (1990). The Self-concept : European perspectives on its development, aspects, and applications. (L. Oppenheimer, Ed.) (1st ed.). Budapest: Springer-Verlag.

Eleftheria, T., Sotiriou, S., \& Doran Ellinogermaniki Agogi, R. (2016). The "Big Ideas of Science" for the school classroom: Promoting interdisciplinary activities and the interconnection of the science subjects taught in primary and secondary education. Journal of Research in STEM Education, 2(2), 72-89.

Erkut, S., \& Marx, F. (2005). 4 schools for WIE. Evaluation Report.

Faber, M., Walton, M., Booth, S., Parker, B., \& Corn, J. (2013). The Golden LEAF STEM Initiative Evaluation Year Two Report-Appendices Consortium for Educational Research and Evaluation-North Carolina. Retrieved from www.goldenleaf.org

Fayer, S., Lacey, A., \& Watson, A. (2017). BLS Spotlight on Statistics: STEM Occupations - Past, Present, and Future. Washington. Retrieved from http://digitalcommons.ilr.cornell.edu/key_workplace

Funk, C., \& Parker, K. (2018). Women and men in STEM often at odds over workplace equity. Washington.

Greenwald, A. G., Banaji, M. R., Rudman, L. A., Farnham, S. D., Nosek, B. A., \& Mellott, D. S. (2002). A unified theory of implicit attitudes, stereotypes, self-esteem, and self-concept. Psychological Review, 109(1), 3-25. https://doi.org/10.1037/0033-295X.109.1.3

Greenwald, A. G., Mcghee, D. E., \& Schwartz, J. L. K. (1998). Measuring Individual Differences in Implicit Cognition: The Implicit Association Test. Journal of Personality and Soclal Psychology, 74(6), 1464-1480.

Greenwald, A. G., Nosek, B. A., \& Banaji, M. R. (2000). Understanding and Using the Implicit Association Test: I. An Improved Scoring Algorithm. Journal of Personality and Social Psychology, 79(6), 197-216. https://doi. org/10.1037/0022-3514.85.2.197

Greenwald, A. G., Nosek, B. A., \& Banaji, M. R. (2003). Implicit Association Test (IAT). Retrieved from https:// www.millisecond.com/download/library/iat/

Griffith, A. L. (2010). Persistence of Women and Minorities in STEM Field Majors: Is it the School That Matters? Economics of Education Review, 29(6), 911-922.

Grossman, J. M., \& Porche, M. V. (2014). Perceived Gender and Racial/Ethnic Barriers to STEM Success. Urban Education, 49(6), 698-727. https://doi.org/10.1177/0042085913481364

Guilford, J. P. (1956). The structure of intellect. Psychological Bulletin, 53(4), 267-293. https://doi.org/10.1037/ h0040755

Guyotte, K. W., Sochacka, N. W., Costantino, T. E., Walther, J., \& Kellam, N. N. (2014). Steam as social practice: cultivating creativity in transdisciplinary spaces. Art Education, 67(6), 12-19. https://doi.org/10.1080/00043 125.2014.11519293

Gwirayi, P., \& Shumba, A. (2007). Students' Self-Concept and Academic Achievement in Zimbabwe: A Preliminary Study. Journal of Psychology in Africa, 17(1-2), 119-122. https://doi.org/10.1080/14330237.2007. 10820155

Hajloo, N. (2014). Relationships Between Self-Efficacy, Self-Esteem and Procrastination in Undergraduate Psychology Students. Iranian Journal of Psychiatry and Behavioral Sciences, 8(3), 42-49.

Huang, G., Taddese, N., \& Walter, E. (2000). Entry and Persistence of Women and Minorities in College Science and Engineering Education. Education Statistics Quarterly, 2(3), 59-60. 
Jackson, J. F. L., Charleston, L. J., Lewis, C. W., Gilbert, J. E., \& Parrish, W. P. (2017). Texas Education Review Arizona's Rising STEM Occupational Demands and Declining Participation in the Scientific Workforce: An Examination of Attitudes among African Americans toward STEM College Majors and Careers.

Jolly, A. (2014, September). STEM vs. STEAM: Do the Arts Belong? Education Week Teacher, 1-3.

Klapp, A. (2018). Does academic and social self-concept and motivation explain the effect of grading on students' achievement? European Journal of Psychology of Education, 33(2), 355-376. https://doi.org/10.1007/ s10212-017-0331-3

Krigman, E. (2014, February). Gaining STEAM: Teaching Science Through Art. U.S. News \& World Report, 1-8. Retrieved from https://www.usnews.com/news/stem-solutions/articles/2014/02/13/gaining-steamteaching-science-though-art

Kuenzi, J. J. (2008). Science, Technology, Engineering, and Mathematics (STEM) Education: Background, Federal Policy, and Legislative Action. Washington. Retrieved from https://fas.org/sgp/crs/misc/RL33434.pdf

Land, M. H. (2013). Full STEAM Ahead: The Benefits of Integrating the Arts Into STEM. Procedia Computer Science, 20, 547-552. https://doi.org/10.1016/j.procs.2013.09.317

Langdon, D., Mckittrick, G., Beede, D., Khan, B., \& Doms, M. (2011). STEM: Good Jobs Now and for the Future. Washington. Retrieved from https://files.eric.ed.gov/fulltext/ED522129.pdf

Lehming, R., Gawalt, J., Cohen, S., \& Bell, R. (2013). Women, Minorities, and Persons with Disabilities in Science and Engineering. Alexandria. Retrieved from https:/www.nsf.gov/statistics/2017/nsf17310/static/downloads/ nsf17310-digest.pdf

Madden, M. E., Baxter, M., Beauchamp, H., Bouchard, K., Habermas, D., Huff, M., ... Plague, G. (2013). Rethinking STEM Education: An Interdisciplinary STEAM Curriculum. Procedia Computer Science, 20, 541546. https://doi.org/10.1016/j.procs.2013.09.316

Malcom, S., \& Feder, M. (2016). Barriers and opportunities for 2-year and 4-year STEM degrees: Systemic change to support students' diverse pathways. Barriers and Opportunities for 2-Year and 4-Year STEM Degrees: Systemic Change to Support Students' Diverse Pathways. National Academies Press.

Markus, H., \& Kunda, Z. (1986). Stability and malleability of the self-concept. Journal of Personality and Social Psychology, 51(4), 858-866. https://doi.org/10.1037/0022-3514.51.4.858

Marra, R. M., Rodgers, K. A., Shen, D., \& Bogue, B. (2009). Women Engineering Students and Self-Efficacy: A Multi-Year, Multi-Institution Study of Women Engineering Student Self-Efficacy. Journal of Engineering Education, 98(1), 27-38. https://doi.org/10.1002/j.2168-9830.2009.tb01003.x

Marsh, H. W., \& Koller, O. (2003). Bringing together two theoretical models of relations between academic self-concept and achievement. In H. Marsh, R. G. Craven, \& D. M. McInerney (Eds.), International Advances in Self Research (1st ed., pp. 17-47). Charlotte: Information Age Publishing.

Marsh, H. W., \& Martin, A. J. (2011). Academic self-concept and academic achievement: Relations and causal ordering. British Journal of Educational Psychology, 81(1), 59-77. https://doi.org/10.1348/000709910X503501

Marsh, H. W., \& Seaton, M. (2013). Academic self-concept. In J. Hattie \& E. M. Anderman (Eds.), International guide to student achievement. (pp. 62-63). New York, NY, US: Routledge/Taylor \& Francis Group.

Maton, K. I., Sto Domingo, M. R., Stolle-Mcallister, K. E., Zimmerman, J. L., \& Iii, F. A. H. (n.d.). Enhancing the Number of African Americans Who Pursue STEM PhDs: Meyerhoff Scholarship Program Outcomes, Processes, and Individual Predictors. https://doi.org/10.1615/JWomenMinorScienEng.v15.i1.20

McClary, T., Zeiber, J. A., Sullivan, P., \& Stochaj, S. (2018). Using Multi-Disciplinary Design Challenges to Enhance Self-Efficacy within a Summer STEM Outreach Program. In 2018 ASEE Gulf-Southwest Section Annual Conference (pp. 1-4). Austin: New Mexico State University. Retrieved from http://digitalcommons.usu. edu/

Mcleod, S. (2008). Likert Scale. Retrieved from https://www.simplypsychology.org/likert-scale.html

Miel, K., Portsmore, M. D., Maltese, A. V., \& Paul, K. (2018). Examining the Interactions Related to Role Modeling in an Elementary Outreach Program (Work in Progress) (No. 126). Salt Lake City. Retrieved from https://peer. asee.org/board-126-examining-the-interactions-related-to-role-modeling-in-an-elementary-outreachprogram-work-in-progress

Miller, J., \& Knezek, G. (2013). STEAM for student engagement. In Society for Information Technology \& Teacher Education International Conference (pp. 3288-3298). New Orleans: Association for the Advancement of Computing in Education (AACE). Retrieved from https://www.learntechlib.org/primary/p/48602/ 
National Science Foundation, \& National Center for Science and Engineering Statistics. (2019). Women, Minorities, and Persons with Disabilities in Science and Engineering: 2019. Alexandria. Retrieved from https:// www.nsf.gov/statistics/wmpd

Nieto, S., \& Bode, P. (2012). Affirming diversity: The Sociopolitical Context of Multicultural Education (6th ed.). White Plains: Pearson Education.

Nosek, B. A., Banaji, M. R., \& Greenwald, A. G. (2002). Harvesting Implicit Group Attitudes and Beliefs From a Demonstration Web Site. Group Dynamics: Theory, Research, and Practice, 6(1), 101-115. https://doi. org/10.1037/1089-2699.6.1.101

Pajares, F. (1996). Self-efficacy beliefs in academic settings. Review of Educational Research, 66(4), 543-578.

Rabalais, M. E. (2014). STEAM: a national study of the integration of the arts into STEM instruction and its impact on student achievement. University of Louisiana Lafayette . Retrieved from https://pqdtopen.proquest.com/ doc/1669973460.html?FMT=ABS

Reinholz, D. L. (2018). Equity during peer conferences: A linguistic comparison by race and gender. Journal of Research in STEM Education, 4(1), 54-67.

Riegle-Crumb, C., King, B., \& Irizarry, Y. (2019). Does STEM Stand Out? Examining Racial/Ethnic Gaps in Persistence Across Postsecondary Fields. Educational Researcher, 48(3), 133-144.

Rinn, A. N., Miner, K., \& Taylor, A. B. (2013). Family context predictors of math self-concept among undergraduate STEM majors: An analysis of gender differences. Journal of the Scholarship of Teaching and Learning, 13(2), 116-132.

Segarra, V. A., Natalizio, B., Falkenberg, C. V., Pulford, S., \& Holmes, R. M. (2018). STEAM: Using the Arts to Train Well-Rounded and Creative Scientists. Journal of Microbiology \& Biology Education, 19(1), 1-7.

Soe, L., \& Yakura, E. K. (2008). Women's Studies What's Wrong with the Pipeline? Assumptions about Gender and Culture in IT Work. Women's Studies, 37(3), 176-201. https://doi.org/10.1080/00497870801917028

Sousa, D. A., \& Pilecki, T. (2013). From STEM to STEAM : Using brain-compatible strategies to integrate the arts (1st ed.). Thousand Oaks: Sage.

Stout, J. G., Dasgupta, N., Hunsinger, M., \& McManus, M. A. (2011). STEMing the tide: Using ingroup experts to inoculate women's self-concept in science, technology, engineering, and mathematics (STEM). Journal of Personality and Social Psychology, 100(2), 255-270. https://doi.org/10.1037/a0021385

Sui-Chu Ho, E. (2003). Students' Self-Esteem in an Asian Educational System: Contribution of Parental Involvement and Parental Investment. The School Community Journal, 13(1), 65-84.

Tesser, A. (2000). On the Confluence of Self-Esteem Maintenance Mechanisms. Personality and Social Psychology Review, 4(4), 290-299.

Thomas, C. R., \& Gadbois, S. A. (2007). Academic self-handicapping: The role of self-concept clarity and students' learning strategies. British Journal of Educational Psychology, 77(1), 101-119. https://doi. org/10.1348/000709905X79644

Ting, Y.-L. (2016). STEM from the perspectives of engineering design and suggested tools and learning design. Journal of Research in STEM Education, 2(1), 59-71.

U.S. Bureau of Labor Statistics. (2009). 2010-11 Editions of the Occupational Outlook Handbook and the Career Guide to Industries. Retrieved from www.bls.gov/news.release/ecopro.toc.htm.

Unfried, A., Faber, M., Stanhope, D. S., \& Wiebe, E. (2015). The Development and Validation of a Measure of Student Attitudes Toward Science, Technology, Engineering, and Math (S-STEM). Journal of Psychoeducational Assessment, 1-18. https://doi.org/10.1177/0734282915571160

Valentine, J. C., DuBois, D. L., \& Cooper, H. (2004). The Relation Between Self-Beliefs and Academic Achievement: A Meta-Analytic Review. Educational Psychologist, 39(2), 111-133. https://doi.org/10.1207/ s15326985ep3902_3

Van Der Veen, J. (2012). Draw Your Physics Homework? Art as a Path to Understanding in Physics Teaching. American Educational Research Journal, 49(2), 356-407. https://doi.org/10.3102/0002831211435521

Williams, J., \& Mangan, J. (2016). The Efectiveness of Using Young Professionals to Infuence STEM Career Choices of Secondary School Students. Journal of Research in STEM Education, 2(1), 2-8.

Williams, J. P. (2014, May 29). Bringing STEM Education to Underserved Communities. U.S. News \& World Report, pp. 1-9. Retrieved from https://www.usnews.com/news/stem-solutions/articles/2014/05/29/ bringing-stem-education-to-underserved-communities 
Yakman, G. (2015). Georgette Yakman's Professional Biography - Short. Retrieved January 3, 2019, from http:// steamedu.com

Yeung, A. S., Craven, R. G., \& Ali, J. (2013). Self-concepts and educational outcomes of Indigenous Australian students in urban and rural school settings. School Psychology International, 34(4), 405-427. https://doi. org/10.1177/0143034312446890

Zatz, M. S., Gates, A. Q., Santiago, D., \& Johnson, S. (2017). Undergraduate Degrees: Increasing Latino Retention and Completion. In Advancing the Collective Impact of Retention and Continuation Strategies for Hispanics and other Underrepresented Minorities in STEM Fields (pp. 1-131). Washington: National Science Foundation. 